\title{
Are there gaps in our understanding of marine plastic pollution?
}

Guest Editor Professor Linda Godfrey is Manager of South Africa's Waste RDI Roadmap Implementation Unit, under which the suite of Marine Plastic Debris papers was prepared. Prof. Godfrey has a PhD in Engineering and an interest in waste management in developing countries, including the opportunities of 'waste' within a circular economy context. EMAlL: LGodfrey@csir.co.za

The leakage of waste plastic into the environment, especially the marine environment, has become an issue of global concern. In response, governments have implemented various measures from plastic product bans $^{1}$, requirements for greater producer responsibility and product design, to ambitious new recycling targets ${ }^{2-4}$. Given the emotive nature of this topic, scientific evidence is crucial to assess the magnitude of the threat posed by marine plastic; to inform public and private sector responses; and to monitor the effectiveness of these responses.

A large body of research has been conducted on the state and ecological impacts of plastic in the South African marine environment over the past five decades. Hughes ${ }^{5}$ was one of the first ecologists to report the impacts of plastic ingestion and entanglement in turtles. Shaughnessy's ${ }^{6}$ research on entanglement of Cape fur seals off South Africa in the 1970s, and Ryan's ${ }^{7}$ work on plastic ingestion by seabirds from southern Africa to Antarctica in the 1980s, provided early insights into the impact of macroand microplastics. Ryan and Moloney's ${ }^{8}$ research on trends in abundance and composition of beach plastic from 1984 to 1989, published 30 years ago in the South African Journal of Science, is now thought to be the first use of the term 'microplastics' in the context of marine plastic pollution.

However, little has been done to consolidate this extensive body of research in order to support decision-makers in assessing the threat of marine plastic to South African ecosystems, human health and the economy. The Department of Science and Innovation, through the Waste RDI Roadmap, initiated a process in May 2019 to produce a 'science review of marine plastic pollution in South Africa'. The aim of this review was to consolidate existing scientific evidence and to use this evidence to assess the current gaps in knowledge and the implications of these evidence gaps. This would inform whether a targeted research agenda on marine plastic pollution is needed for South Africa. Five science review papers were prepared and are presented in this issue of the South African Journal of Science. They provide valuable insights into the sources, pathways, fates and resultant impacts of marine plastic debris in South Africa, highlighting key evidence gaps. Some of these evidence gaps are summarised here.

Verster and Bouwman estimate that between 15000 and 40000 tonnes per year of waste plastic is carried into South Africa's oceans from landbased sources. This is six-fold less than the estimate by Jambeck et al. ${ }^{9}$ who placed South Africa 11th in the world in terms of mass of mismanaged plastic waste. However, the authors acknowledge that while most marine plastic originates inland, scientific evidence on the land-based sources of marine plastic and the role of inland water systems (rivers, dams, estuaries) as temporary sinks and potential long-term secondary sources, is scarce. The potential impact of microplastics on drinking water sources, the efficacy of waste-water treatment works in removing plastics, and the resultant management of treatment sludge, need to be better understood.

This paucity of data on land-based sources of plastics entering the ocean is reconfirmed by Ryan, who notes that 'either we are greatly overestimating the amounts of plastic entering the sea, or we are failing to measure a major sink of marine plastics'. The amounts of litter stranding on our beaches and floating at sea are at least an order of magnitude less than those predicted by the model of global leakage. ${ }^{9}$ The transport and fate of plastics in the South African marine environment, and changes over time, are relatively well understood given the amount of research already undertaken on these topics. The coastal surveys that have been conducted since the 1980s provide an important foundation from which to build future monitoring programmes.

Research on the ecological impacts of plastics in the marine environment has the longest track record in South Africa. However, Naidoo et al. note that our understanding of the ecological impacts on populations of marine species is limited, and the transfer of plastics along the food chain to humans, and associated impacts on human health, remain unknown. Given the economic importance of South Africa's fishing industry, further research on the effects of plastic on commercial species of fish and invertebrates, including species processed to fish meal, is recommended. As noted by the authors: 'This gap must be filled in order to make predictive decisions in regard to safety for consumption.' Given the limited R\&D funding available in South Africa, we need to decide what research we should undertake ourselves, and what we can leave to the international research community.

Despite decades of research on plastics in South Africa's oceans, research on the impacts on ecosystem services and the economy is almost nonexistent. Arabi and Nahman point out that while pockets of information are available on the impacts on recreation and tourism, there is an urgent need 'to quantify the environmental and social impacts of marine plastic debris in economic terms, in order to provide an understanding of the costs of inaction'. In particular, research is needed on the impacts on ecosystem services relating to fisheries and aquaculture, heritage, habitat provision, biodiversity and nutrient cycles, as well as the associated direct and indirect economic impacts and non-market costs.

The series of review papers is well summed up by Ryan et al. who note: 'In South Africa, we have a long history of studying marine plastics, and we already know enough about their impacts on marine systems to justify implementing policies to reduce the leakage of waste plastic into the environment.' Monitoring programmes will be critical to assessing the effectiveness of these policy interventions. Given that most of South Africa's marine plastic pollution originates on land, it is important to implement monitoring programmes close to the points of leakage.

\section{References}

1. United Nations Environment Programme. Single-use plastics: A roadmap for sustainability [webpage on the Internet]. c2018 [cited 2020 Apr 15]. Available from: https://wedocs.unep.org/handle/20.500.11822/25496

2. European Commission. A new Circular Economy Action Plan: For a cleaner and more competitive Europe [document on the Internet]. c2019 [cited $2020 \mathrm{Apr}$ 15]. Available from: https://eur-lex.europa.eu/resource. html?uri= cellar:9903b325-6388-11ea-b735-01aa75ed71a1.0017.02/ DOC_1\&format=PDF

3. European Union. Directive (EU) 2018/852 of the European Parliament and of the Council of 30 May 2018 amending Directive 94/62/EC on packaging and packaging waste [document on the Internet]. c2018 [cited 2020 Apr 15] Available from: https://eur-lex.europa.eu/legal-content/EN/TXT/PDF/?uri=CE LEX:32018L0852\&from =EN

4. European Union. Directive (EU) 2019/904 of the European Parliament and of the Council of 5 June 2019 on the reduction of the impact of certain plastic products on the environment [document on the Internet]. c2020 [cited 2020 Apr 15]. Available from: https://eur-lex.europa.eu/legal-content/EN/TXT/PDF/ ?uri=CELEX:32019L0904\&from =EN

5. Hughes GR. The sea turtles of south-east Africa. 1: Status, morphology and distributions. Oceanographic Research Institute investigative report. Durban: South African Association for Marine Biological Research; 1974.

6. Shaughnessy P. Entanglement of Cape fur seals with man-made objects. Mar Pollut Bull. 1980;11(11):332-336. https://doi.org/10.1016/0025326x(80)90052-1

7. Ryan PG. The incidence and characteristics of plastic particles ingested by seabirds. Mar Environ Res. 1987;23:175-206. https://doi.org/10.1016/01411136(87)90028-6

8. Ryan PG, Moloney CL. Plastic and other artefacts on South African beaches: Temporal trends in abundance and composition. S Afr J Sci. 1990;86:450-452.

9. JambeckJ, GeyerR, Wilcox C, Siegler TR, Perryman M, Andrady A, et al. Plastic waste inputs from land into the ocean. Science. 2015;347(6223):768-771. https://doi.org/10.1126/science.1260352 